\title{
Health and safety in research laboratories
}

Fred Grover and Peter Wallace discuss some of the problems of applying the UK's Health and Safety at Work Act to workers in research laboratories THE UK Health and Safety at Work
Act, 1974 differs from previous legislation in one major respect: it applies to all persons at work and, therefore, to many people not covered by earlier legislation. Laboratory workers are among these 'new entrants' and although previous regulations have applied in part to their work there has never before been legislation which is relevant to all their activities. Inspectors appointed under the Act have only recently begun to examine those laboratories not previously visited and in due course they will all come under scrutiny. It is interesting to wonder how the inspectors' findings will compare with those in industry. Will present standards be acceptable to them?

Common room conversations reveal that a large proportion of laboratory workers think that safety standards are already adequate and that inspectors would find little cause for complaint. It is true that most well run laboratories have been safety conscious for many years and that accident rates have been relatively low; but this happy state of affairs has often been the result of bitter experience. Any hint of complacency is a danger signal: to rely on past record rather than future improvement can only lead to declining standards and ultimate catastrophe.
The problem with the Act is that it is at once precise and vague; precise in that it defines the duties of all employees and employers and vague in the way it does not stipulate what is considered to be a safe approach to any specific task. It will doubtless result in the proliferation of more specific regulations in the light of experience and case law but for the time being its operation must depend on its interpretation by individual inspectors.

Accidents do not just happen but arise from numerous and varied causes or are brought about by several apparently unrelated factors, each of which in isolation would not have been considered hazardous.

Clearly an inspector can only assess the situation from what he sees or from what is reported to him; he has no way of determining the competence, or otherwise, of individual workers. Presumably, he will be primarily concerned with the working conditions and with the safety policy of the laboratory. His experience will enable him to make a fairly accurate assessment based on a general impression gained from inspection of the laboratories, discussions with staff and examination of accident records and safety committee reports. One assumes also that inspectors will, where necessary, call in specialist advisers to give guidance on safe working methods and that in time the

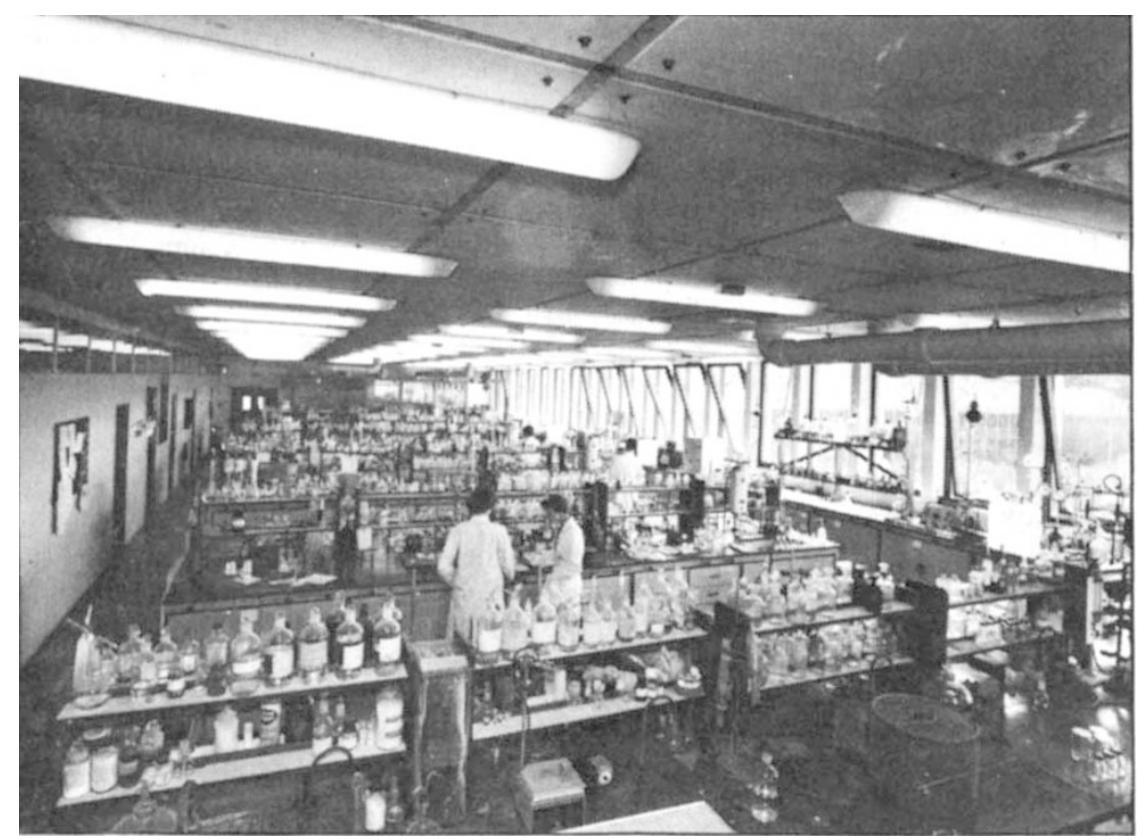

majority of forseeable hazards can be virtually eliminated.

Thorough inspection of the premises and working methods, however, may not reveal any significant defects; but this does not guarantee that accidents will not occur. The provision of fire extinguishers does not prevent a fire from starting and the presence of an autoclave in a bacteriology department does not prevent the escape of pathogenic organisms.

What then can be done about the less obvious but equally significant behavioural problems which cannot be overcome either by legislation or inspection? What evidence is there to support the view that laboratory staff are inherently safer than other workers? To assume that a higher level of education is a password to safety is not only turning a blind eye to the problem but may well be a hazard in itself. Immuunity from accidents is not a bonus issued free with every degree or certificate of technical ability. Carelessness, fatigue, lack of concentration, shortage of time, even bravado are just some of the possible causes of accidents but perhaps the dominant factor is simply a lack of common sense.

\section{Experience and training}

Common sense is not a subject which can be taught academically but is acquired through experience and training. The young employee, entering the laboratory environment for the first time, is potentially more at risk than his experienced colleagues and will require more supervision and guidance. A very junior technician was badly burned with sulphuric acid which he was pouring from a winchester into a small test tube, holding the bottle in one hand and the tube in the other. He had simply not realised the impossibility of doing this safely.

The more experienced worker coming from an organisation where safety is not taken seriously can bring problems with him. He will probably have survived for years with no major mishap and will not take kindly to working within a new set of rules. Academic freedom is, of course, essential to scientific progress but like every other freedom it must be limited by a consideration for the rest of society.

A biochemist, having been advised of the dangers of perchloric acid at 0 high temperatures, insisted that no other oxidant would be suitable for

Fred Grover is Safety Adviser at the Medical Research Council. Peter Wallace is Laboratory Superintendent at the Nuffield Institute of Comparative Medicine of the London Zoological Society. 
his particular need and that what he was about to do was a standard technique. The reagent was added to a number of tubes in an aluminium heating block and within minutes the resulting explosion removed all the glass from the fume cupboard in which he was working.

Changing techniques can lead an experienced worker into areas totally new to him. A parasitologist of many years experience became involved in a technique using ${ }^{125} \mathrm{I}$ which he counted on planchettes as a solid iodinated protein. He soon discovered that the protein would not remain in the planchettes when they were handled and was advised to add an adhesive to fix the material. This idea did not appeal to him and he placed the planchettes on the bench and sprayed them with an aerosol of microscope slide fixative which he had been in the habit of using in his normal work. Within seconds he had emptied the planchettes and contaminated his laboratory.

Some years ago the need for specialisation was not so apparent as it is today and both education and training were of a more general nature. Basic skills which were once considered so essential now tend to be overlooked or regarded as the province of some other discipline. A pathologist, having received limited training in chemistry, may be totally unaware that hypochlorites and formaldehyde react, possibly even in the vapour state, to form Bis-chloromethyl ether, a potent carcinogen.

It used to be customary to refer to a chemist but it is now fashionable to think in terms of a plastics chemist, a pesticide chemist or a paint chemist.

Each of these may know nothing of the others' technology or of the associated hazards. A virologist and a parasitologist jointly became involved in a new technique which required the addition of sodium azide to several hundred test samples. After some months it was discovered that they had routinely disposed of their residues in the sink, totally unaware of the explosive properties of azides.

The worker whose time is in great demand is often under such pressure that he becomes forgetful. A biochemist needing distilled water of a higher purity than that provided by the departmental still, set up a glass still over a gas burner and rushed off to a meeting. In his absence the flask cracked, extinguishing the burner and filling the room with gas.

The external standard source of a liquid scintillation counter became wedged in the pneumatic transfer system and a workshop technician. familiar with the equipment, was called in to clear the fault. Complete dismantling would have taken some

\section{Testing for mutagens}

considerable time but having been told that results were needed urgently he attempted a quick cure by disconnecting the flexible tube and blowing into it, without success. As he released the pressure the radioactive source blew back into his mouth. Fortunately he did not swallow it.

\section{Health as well as safety}

Discussions and publications relating to the Act have laid great emphasis on the safety aspect but health and welfare which also featured in the original document have received little attention. There are countless laboratory situations which may not result in accidents but which are decidedly unhealthy. Inadequate ventilation may result in prolonged exposure to low levels of toxic vapours which might produce clinical symptoms in later life. The long term carcinogenic properties of various groups of compounds are still something of a mystery but it is abundantly clear that risk is related to concentration and period of exposure. Many occupational diseases of the past were simply not associated with exposure to toxic materials and as the list of such compounds grows it becomes apparent that we are not yet out of the wood.

The whole problem of bio-hazards is still somewhat nebulous (there is apparently no legal definition of the word) and it is only recently that any serious attempt has been made to distinguish between dangerous and very dangerous pathogens. Labelling an organism low risk as opposed to high risk does not imply that it is safe to handle under all conditions, an assumption that may well be made by the inexperienced.
There are many examples of major and minor accidents and of near-misses which add to an awareness of the shortcomings. Management has a clearly defined obligation under the Act to provide conditions and training to ensure safety "so far as is reasonably practicable" (a phrase which occurs no less than fourteen times in the first six sections).

A detailed examination of laboratory surroundings is clearly a good starting point and the rectification of obvious weaknesses may well satisfy the inspectors. But this, is itself, is not sufficient: health and safety are a philosophy and every available means must be used to instill correct attitudes among staff at all levels. The Act refers to employers and employees but in many respects senior staff may be regarded as either or both.

Good housekeeping, training, supervision and discipline are all vital but constant vigilance is probably that all important factor in reducing accident levels. The cost of accidents is too great, both in material terms and in terms of human suffering. to allow for complacency.

What once may have been considered as little more than a moral obligation is now a legal commitment. This year, many organisations are to introduce Safety Committees whose terms of reference and modus operandi must be clearly defined and agreed. In some establishments this is regarded as another piece of time wasting bureaucracy and problems will inevitably arise. The Health and Safety at Work Act is a genuine attempt to reduce the awesome toll of death and injury which for too long has gone unchecked. 